Souza M.L. e Colaborador - População dos Estados da Região Sul do Brasil e o Compromisso Social da Enfermagem com o Idoso. Rev. Bras. Enf.; RS.36: 192 - 199, 1983.

10. FIBGE. Recenceamento geral do Brasil, Rio Grande do Sul, Santa Catarina e Paraná 1960, 1970 e 1980.

11. FIBGE. Indicadores Sociais. Tabelas Selecionadas. 1979.

12. HORTA, W. de A. A assistência de Enfermagem ao Adulto Idoso. Enf. Novas Dimensões. 4 (5): 268-73, 1978.

13. LEA, M. Quem tem medo de envelhecer? Rio de Janeiro, Record, 1981.

14. QUADRA, A. A. F. et alii. Marcos conceituais do atendimento integral a o idoso. RPH 29 (1): 3-8, 1981.

15. SVANBORG, A. A idade avançada e em boa forma. A saúde no mundo. 16-19, abril 1979 (publicação da OMS).

16. THOMAS, R. G. Os idosos num mundo em transformação. A saúde no mundo. 3-7, abril 1979 (publicação da OMS).

17. TIMIO, M. Classes sociales y enfermedad. Introducción a una epidemiologia diferencial. Editorial Nueva Imagen. México. DF. 1980. p. 121.

18. VIEDMA. C, Um desafio mundial. A saúde no mundo. 20-22, abril 1979 (publicação da OMS).

\title{
AVALIAÇÃO DE UM PROGRAMA DE ASSISTÊNCIA PRIMÁRIA DE SAÚDE NA ÁREA PERIURBANA
}

* Rosana Lúcia Alves de Vilar

** Mary Anne Small

$\mathrm{ReBEn} / 09$

Vilar R. L. A. e Colaboradora - Avaliação de um Programa de Assistência Primária de Saúde na Área Periurbana Rev. Bras. Enf.; RS 36: 199 - 212; 1983

\section{RESUMO}

Foi implantado e executado um Programa de Assistência Primária de Saúde em duas comunidades da área periurbana da cidade de Natal-RN. A finalidade deste programa foi de elevar o nível de saúde da comunidade, e seu elemento-chave era a participação comunitária através, principalmente, do trabalho da promotora de saúde. Será detalhado o desenvolvimento do programa e apresentada uma avaliação baseada em mudanças mensuráveis de práticas de saúde e utilização dos serviços de saúde, como observado nestas comunidades no período de dois anos.

\section{INTRODUÇÃO}

O Estado do Rio Grande do Norte vem sofrendo um processo de urbanização crescente. No censo de 1970 , a população urbana foi de $51,16 \%$, e, em 1980 , com uma população total de 1.899 .725 habitantes, este percentual subiu para 58,73\%. A taxa de crescimento populacional do ano de 1980 ainda mostra, com bastante evidência, este aumento populacional, que, para todo o Estado, foi de 2,04\% e, para a capital - Natal, com 416.906 habitantes, foi de 4,65\%. para ser mais explícito, se o crescimento continuasse neste ritmo, em 34 anos a população do Estado duplicaria, enquanto que isto ocorreria, na capital, em 15 anos. (SINOPSE RN-1980).

* Professora Assistente do Departamento de Enfermagem, Universidade Federal do Rio Grande do Norte, Brasil.

**Enfermeira Educadora de Saúde Comunitária do Projeto HOPE, em Millwood, Virginia, E. U. A., Professora Visitante do Departamento de Enfermagem da Universidade Federal do Rio Grande do Norte de 1974-1981. 
Vilar R.L.A. e Colaboradora - Avaliação de um Programa de Assistência Primária de Saúde na Área Periurbana. Rev. Bras. Enf.; RS.36: 199 - 212, 1983.

Este crescimento desordenado é decorrente de dois fenômenos: o crescimento natural e as migrações ocorridas da população rural, atraídas pelas supostas oportunidades da zona urbana. Ao lado disto, há também o aparecimento de todos os problemas decorrentes das migrações, ocasionando disparidades sócio-econômicas e conseqüente baixo nível de vida e saúde.

Dados colhidos em quatro comunidades da área periurbana de Natal vêm confirmar o que já foi descrito.

Esta área que fica a uma distância entre 10 e $13 \mathrm{~km}$ do centro da cidade, possuía uma população de $66,36 \%$ com menos de 20 anos de idade, e o tamanho médio da familia era de 6,$2 ; 60,8 \%$ das casas era provido de energia elétrica e apenas $45,5 \%$ tinha abastecimento público de água.

Outro indicador bastante representativo da qualidade de vida era a incidência de desnutrição nas crianças com menos de 5 anos de idade. Utilizando a classificação de Gomes, que relaciona peso com idade, foram observados os seguintes resultados:

$\begin{array}{lr}\text { peso normal } & 40,5 \% \\ \text { desnutrição - 1. grau } & 44,8 \% \\ \text { desnutrição - 2. grau } & 13,5 \% \\ \text { desnutrição - 3. grau } & 1,1 \%\end{array}$

Um grupo de comunitários e enfermeiros que trabalhavam na área elaboraram e implantaram um programa de Assistência Primária de Saúde com a finalidade de melhorar o nível de saúde destas comunidades.

O programa incluía em suas características os elementos considerados essenciais, como: participação comunitária, tecnologia adequada e açōes básicas. Estas açōes eram dirigidas, na sua maioria, para o grupo materno-infantil, considerando o percentual deste grupo na população e a repercussão de melhorias nesta faixa num período próximo.

O programa visava à promoção de hábitos positivos de saúde como a utilização do pré-natal, puericultura, medidas de higiene e amamentação, que eventualmente contribuiriam para elevar o nível de saúde.

Dentro da filosofia de assistência primária de saúde, que visa colocar ao alcance universal da comunidade os cuidados essenciais de saúde, a participação comunitária é um elemento-chave.

Há várias interpretaçōes do processo de participação comunitária, dependendo da real finalidade do programa. Em certas situações, esta participação é utilizada como meio para facilitar a execução de atividades pré-definidas, ajudando assim o alcance dos objetivos propostos por planos centrais. É um tipo de participação passiva e controladora. Em outras situaçōes há participação nos níveis de planejamento e ação. Desta forma, a comunidade torna-se responsável por sua própria saúde na busca de solução dos seus problemas. É um tipo de participação ativa e transformadora.

O tipo de participação que houve no programa de Assistência Primária de Saúde pode ser considerado como a da segunda forma acima. Os resultados em termos mensuráveis levaram certo tempo para serem obtidos porque foram necessárias algumas mudanças no comportamento das pessoas e instituiçōes. Estes resultados serão apresentados e comentados mais adiante.

A conceituação de assistência primária de saúde enfatiza o papel da comunidade para seu desempenho, mas também é essencial que os profissionais sejam capacitados nesta metodologia. Vale ressaltar que a tendência anterior era de preparar técnicos especialistas, enquanto este tipo de assistência exige um preparo generalista, voltado para a comunidade. $\mathrm{O}$ programa assume também o seu papel na formação de enfermeiro, servindo de campo de estágio, promovendo, concomitantemente, a integração ensino-serviço.

Foi elaborado um modelo para avaliar a eficácia do programa. A metodologia utilizada será descrita posteriormente, seguida pela recomendação baseada nos resultados.

\section{DESCRIÇĀO}

\subsection{Histórico}

No ano de 1973, foi iniciado, no Centro de Saúde do bairro da Cidade da Esperança, situado na periferia de Natal, o atendimento à criança sadia, através do Serviço de Puericultura, como tentativa de diminuir os problemas mais freqüentes na idade infantil, principalmente no $1^{\circ}$. ano de vida, ligados, na sua grande maioria, a causas evitáveis.

No ano seguinte, foi feita uma primeira avaliação do modelo criado, e foi bastante evidente a melhoria no estado de imunização e nutrição das crianças inscritas no serviço, comparada a um grupo 
Vilar R.L.A. e Colaboradora - Avaliação de um Programa de Assistência Primária de Saúde na Área Periurbana. Rev. Bras. Enf.; RS.36: 199 - 212, 1983.

de crianças com a mesma idade que também foram atendidas no Posto de Saúde em outros serviços. Este grupo de controle ficou nos limites de desnutrição de primeiro grau e pesou cerca de $10 \%$ menos por criança. Foram também observados os óbitos ocorridos e o tempo de hospitalização das crianças nos dois grupos. No grupo de crianças da puericultura, não houve óbitos, ocorrendo uma hospitalização de 18 horas; no segundo grupo de crianças, que não eram da puericultura, houve 4 óbitos e 122 dias de hospitalização. Estes resultados ocasionaram uma expansão de serviço para aumentar a cobertura das crianças na área. Dois anos após, em 1975, foi realizada uma segunda avaliação, onde foi novamente comprovada a eficácia de serviço e também foi constatado que apenas $25 \%$ das crianças do bairro estavam sendo beneficiadas, porém o número de crianças que estavam inscritas era muito grande, já dificultando a assistência. Isto se explicou pelo fato de quatro bairros próximos (Cidade Nova, Felipe Camarão, Bom Pastor e Nazaré) também utilizarem o Centro de Saúde da Cidade da Esperança. A partir daí, foi sentida a necessidade de ampliação e descentralização da assistência para melhor atender à população.

No ano anterior (1974), foi criado, na Universidade Federal do Rio Grande do Norte, o curso de graduação em Enfermagem, que, neste período da avaliação, necessitava de um campo de estágios para os alunos da disciplina Introdução à Saúde Pública. Considerando as condiçōes sócio-econômicas dos quatro bairros circunvizinhos da Cidade da Esperança,já citados anteriormente, o bairro da Cidade Nova foi escolhido para, nele, ser iniciado um trabalho que começou com um levantamento sanitário feito pelos alunos do Curso de Enfermagem. O resultado deste levantamento mostrou que a maioria da população utilizava o Centro de Saúde da Cidade da Esperança e que a principal razão da procura do Centro foi doença. Foram citados alguns problemas que afetavam o bairro, e, entre eles, estava a falta de assistência de saúde no próprio bairro.

O resultado deste levantamento foi apresentado ao Conselho Comunitário do bairro recentemente formado, que se propôs a tentar solucionar o problema da falta de assistência, oferecendo a mãode-obra para construção de uma unidade de saúde.

No ano seguinte, em 1976, foi feito um levantamento sanitário em outro bairro (Felipe Camarão), com constatações semelhantes e interesse da comunidade de colaborar para conseguir uma unidade de saúde para o bairro. Foram construídas as duas unidades de saúde pelo sistema de mutirão, cuja mão-de-obra consistia dos residentes da comunidade e o material doado por órgãos governamentais. Após a construção da unidade de saúde da Cidade Nova (1976), as duas comunidades solicitaram uma vacinação em massa contra a tuberculose, ante a alta incidência da doença em Cidade Nova. Foram feitos testes de PPD, vacina BCG e encaminhamentos. A campanha contou com a colaboração voluntária de um grupo de senhoras residentes nos dois bairros, que prestaram serviços considerados de grande utilidade para o êxito da campanha, como divulgação e ajuda na organização no dia da vacina. Depois da campanha, estas senhoras resolveram continuar o trabalho em prol da saúde da comunidade e solicitaram do grupo de professores e estudantes do Curso de Enfermagem envolvidos na campanha uma orientação técnica sobre cuidados com a saúde. Foi formada, então, uma sociedade de saúde que recebeu um ciclo de palestras sobre higiene do lar e ficou reunindo-se sem atribuiçōes definidas para discutir problemas ligados à saúde da comunidade.

Como foi comentado anteriormente, o objetivo inicial para melhorar e ampliar a assistência era de descentralizar os serviços de saúde para as quatro comunidades, mas, depois de iniciado o trabalho em Felipe Camarão, o grupo envolvido sentiu a necessidade de parar para uma avaliação. Os recursos disponíveis para construir, treinar, executar, supervisionar, equipar, manter e avaliar eram bastänte limitados, tornando difícil a manutenção do que havia sido inovado.

Após o término da construção do Posto de Saúde de Felipe Camarão, em 1978, o grupo envolvido no trabalho comunitário decidiu melhorar o modelo de assistência primária nas duas comunidades e criar um sistema para avaliar os resultados da execução deste novo modelo. Assim, poder-se-iam fazer recomendações, garantindo a continuidade do trabalho ou a reprodução do mesmo em outra área, baseacio em fatos concretos.

A seguir, apresentamos o Quadro I, resumindo as atividades ocorridas anualmente de 73/81. 
Vilar R.L.A. e Colaboradora - Avaliação de um Programa de Assistência Primária de Saúde na Área Periurbana. Rev. Bras. Enf.; RS.36: 199 - 212, 1983.

\section{QUADRO I}

\begin{tabular}{|c|c|c|}
\hline \multicolumn{2}{|c|}{ ANO } & ATIVIDADES \\
\hline \multirow{6}{*}{$\begin{array}{l}\mathrm{H} \\
\mathrm{I} \\
\mathrm{S} \\
\mathrm{T} \\
\mathrm{O} \\
\mathrm{R} \\
\mathrm{I} \\
\mathrm{C} \\
\mathrm{O}\end{array}$} & 1973 & - Criação do Serviço de Puericultura no Posto de Saúde da Cidade da Esperança \\
\hline & 1974 & - Primeira avaliação de Serviço de Puericultura e ampliação do mesmo \\
\hline & 1975 & $\begin{array}{l}\text { - Segunda avaliação do Serviço de Puericultura da Cidade da Esperança } \\
\text { - Levantamento sanitário do bairro da Cidade da Esperançá } \\
\text { - Formação do Conselho Comunitário da Cidade Nova }\end{array}$ \\
\hline & 1976 & $\begin{array}{l}\text { - Construção da Unidade Sanitária da Cidade Nova } \\
\text { - Levantamento sanitário no bairro de Felipe Camarão } \\
\text { - Formação da Sociedade de Saúde nos dois bairros (Cidade Nova e Felipe Camarão) }\end{array}$ \\
\hline & 1977 & - Construção da Unidade Sanitária de Felipe Camarão \\
\hline & 1978 & - Inauguração da Unidade Sanitária de Felipe Camarão \\
\hline \multirow{3}{*}{$\begin{array}{l}\mathrm{I} \\
\mathrm{N} \\
\mathrm{T} \\
\mathrm{E} \\
\mathrm{R} \\
\mathrm{V} \\
\mathrm{E} \\
\mathrm{N} \\
\mathrm{C} \\
\AA\end{array}$} & 1979 & $\begin{array}{l}\text { - Elaboração e execução do modelo de Assistência Primária de Saúde } \\
\text { - Formação do grupo de promotoras de saúde }\end{array}$ \\
\hline & 1980 & Execução e modelo de Assistência Primária de Saúde \\
\hline & 1981 & - Execução e avaliação do modelo de Assistência Primária de Saúde \\
\hline
\end{tabular}

\subsection{Execução}

\subsubsection{Assistência}

O novo modelo de assistência primária de saúde elaborado visava, prioritariamente, à atenção do grupo materno-infantil. Foi criado com ele um sistema para avaliar a intervenção, que será detalhada no próximo item.

O modelo consistia basicamente em facilitar o acesso da população aos serviços básicos de saúde, através dos mecanismos de descentralização dos serviços, extensão de cobertura e participação comunitária, todos considerados interdependentes.

O Quadro II mostra os serviços oferecidos pelos Centros de Saúde e a equipe de saúde existente até o mês de junho de 1981. No primeiro ano da implantação, este quadro foi diferente, tanto nos serviços oferecidos quanto na equipe de saúde. (Ver quadro na página seguinte).

Durante o primeiro semestre de 1979, foram feitas algumas reuniōes e levantamentos junto às sociedades de saúde e aos Centros de Saúde dos dois bairros, com a finalidade de preparar a área para a implantação do novo modelo de assistência. Um conceito que sempre orientou o trabalho foi o de aproveitar o que já existia, melhorando ou fazendo as modificações necessárias.

A estrutura dos dois Centros foi bastante diferente. O da Cidade Nova, aproveitando um pequeno espaço atrás do grupo escolar, consistia de duas salas, uma despensa e um terraço coberto, que servia de sala de espera. A Unidade de Felipe Camarão foi construída seguindo um modelo padrão, com oito dependências. Sua equipe era formada por dois médicos, um dentista, dois auxiliares e dois atendentes de enfermagem. A Unidade da Cidade Nova tinha apenas três atendentes e um médico, algumas vezes por semana. 
Vilar R.L.A. e Colaboradora - Avaliação de um Programa de Assistência Primária de Saúde na Área Periurbana. Rev. Bras. Enf.; RS.36: 199 - 212, 1983.

\section{QUADRO II}

Quadro 2.1. - Serviços oferecidos pelo Centro de Saúde do Grupo Experimental

\begin{tabular}{|c|c|c|}
\hline Serviço & Cidade Nova & Felipe Camarão \\
\hline Promotoras & + & + \\
\hline Puericultura $(0-4$ anos $)$ & + & + \\
\hline Pediatria $(0-12$ anos $)$ & + & + \\
\hline Pré e Pós-natal & + & + \\
\hline Prevenção do Câncer & - (encaminha) & + \\
\hline Ginecologia & - (encaminha) & 3vezes por semana \\
\hline Clínica Geral & uma vez por semana & 2 vezes por semana \\
\hline Controle e TTT de TB & + & + \\
\hline Saúde Mental & - (encaminha) & -(encaminha) \\
\hline Laboratório & - (encaminha) & + \\
\hline Vacina & + & + \\
\hline Injeção e Curativo & + & + \\
\hline $\mathrm{PNS}$ & + & desde 1980 \\
\hline Educação para saúde & + & + \\
\hline Farmácia & + (limitado) & + (limitado) \\
\hline Planejamento Familiar & + & + \\
\hline Odontológico & & + \\
\hline $\begin{array}{l}\text { Controle e Tratamento } \\
\text { das Doenças Venéreas }\end{array}$ & - (encaminha) & - (encaminha) \\
\hline
\end{tabular}

Os serviços nas duas Unidades eram de atendimento médico, distribuição de medicamentos, curativos, injeções, imunização e planejamento familiar. Em Felipe Camarão, tinha ainda exodontias, e, em Cidade Nova, a suplementação alimentar e a visita domiciliar.

No mês de abril de 1979, foram implantados os serviços de puericultura e pré-natal pelo grupo de docentes e discentes de Enfermagem envolvidos no programa, coordenando o mesmo com a colaboração da equipe do Centro de Saúde e comunitários.

A puericultura atendia lactentes inicialmente até dois meses de idade. No primeiro ano, eram 12 consultas; no segundo, 4; no terceiro e quarto, 2. Das 20 consultas, 12 eram de enfermagem, e 8, do médico. Além das imunizações exigidas pelo Ministério da Saúde, verificação do crescimento e desenvolvimento e orientações individuais e coletivas sobre higiene e nutrição adequada fizeram parte de atendimento.

O pré-natal atendia qualquer gestante que procurasse ou fosse encaminhada do serviço. Eram feitas consultas médicas e de enfermagem, exames laboratoriais, exame obstétrico e orientações sobre assuntos ligados ao ciclo grávido-puerperal.

Neste período de dois anos, houve também programações contínuas de saúde junto às escolas e organizações comunitárias, com a finalidade de debater e tentar solucionar problemas de saúde do bairro.

A Unidade de Saúde tornou-se um verdadeiro centro comunitário, e o enfermeiro passou a exercer suas funções dentro dos limites de um bairro, e não de um prédio.

Houve algumas modificações na equipe de saúde, que constaram da contratação de duas enfermeiras pela Secretaria de Saúde, como resultado das reivindicações das duas comunidades.

Estas enfermeiras assumiram a coordenação do programa, o que foi, de certa forma, facilitado em virtude de as mesmas já terem trabalhado no programa como estagiárias.

$\mathrm{O}$ espaço físico e horário de atendimento também sofreram algumas modificações para melhor atender à demanda, porém, o modelo implantado não sofreu mudanças, possibilitando assim uma avaliação mais correta da sua eficácia. 
Vilar R.L.A. e Colaboradora - Avaliação de um Programa de Assistência Primária de Saúde na Área Periurbana. Rev. Bras. Enf.; RS.36: 199 - 212, 1983.

QUADRO III

INTERRELAÇÃO EXISTENTE ENTRE OS PARTICIPANTES DO PROGRAMA E OS COMPONENTES BÁSICOS

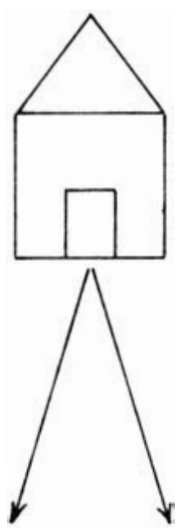

DESCENTRALIZAÇÃO
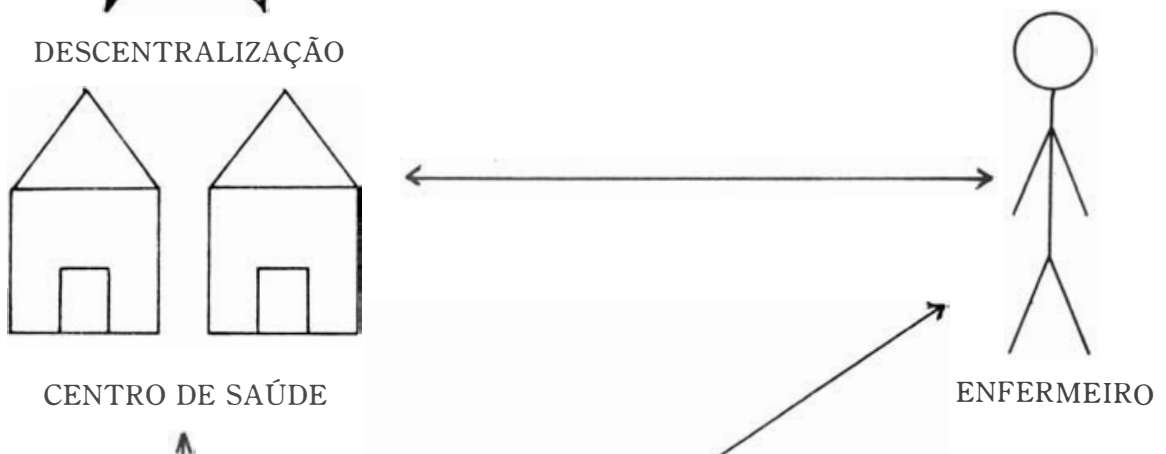

CENTRO DE SAÚDE

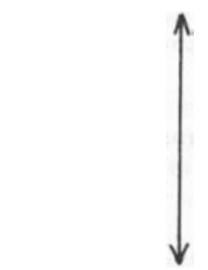

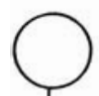
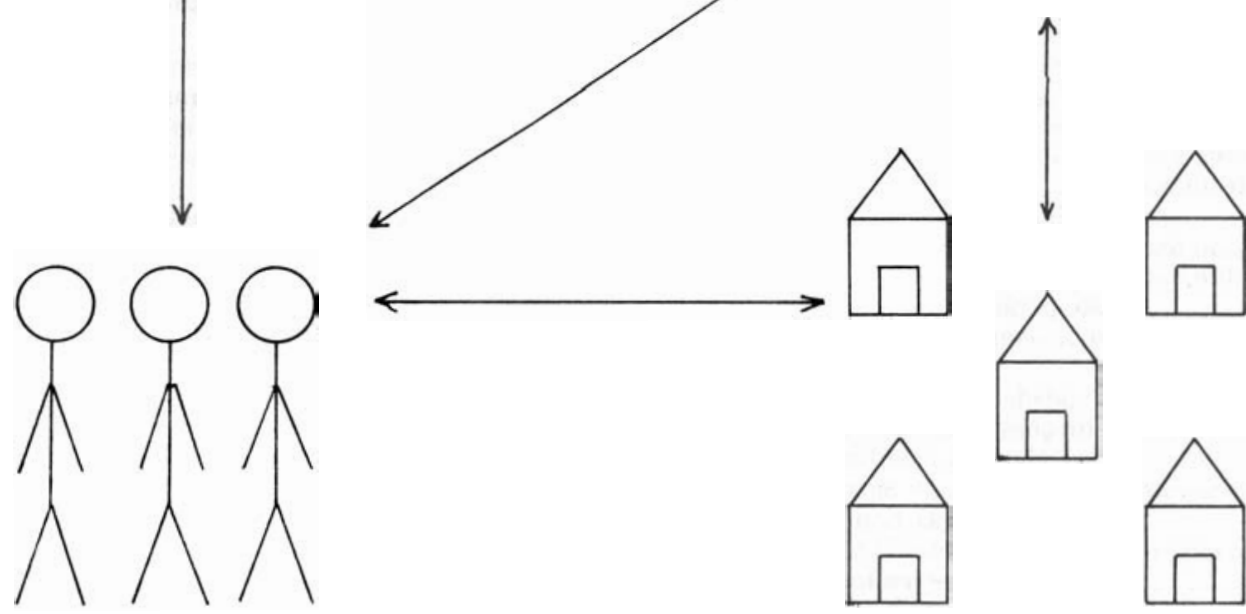

PROMOTORAS DE SAÚDE 
Vilar R.L.A. e Colaboradora - Avaliação de um Programa de Assistência Primária de Saúde na Área Periurbana. Rev. Bras. Enf.; RS.36: 199 - 212, 1983.

\subsubsection{Treinamento}

O treinamento do pessoal para trabalhar na área foi desenvolvido visando à máxima integração de todas as categorias envolvidas - estudantes, equipe de enfermagem e membros da comunidade (promotoras de saúde), e representou um dos pontos-chave para êxito do programa.

O modelo de assistência e avaliação assumiu também seu papel na formação do enfermeiro, visto que a parte prática de uma disciplina - Assistência Primária de Saúde, do Curso de Habilitação em Enfermagem de Saúde Pública - era desenvolvida na área. O conteúdo desta disciplina focalizava conhecimentos relativos ao papel do enfermeiro na assistência primária, preparando o estudante para desenvolver atividadfs: como: diagnóstico de saúde e planejamento de ações de assistência a grupos populacionais, treinamento e supervisão de promotoras de saúde. Ligados a esta disciplina, um total de 45 alunos teve oportunidade de passar pelo programa, durante 4 anos.

Além destas atividades curriculares, eram desenvolvidas outras atividades por estudantes que participavam como bolsistas de extensão universitária. Eles recebiam um treinamento especial para serem entrevistadores e para colaborarem na intervenção e avaliação, desenvolvendo atividades semelhantes às do grupo de alunos. Durante os anos de 1979, 1980 e 1981, um total de 37 alunos bolsistas prestou a sua colaboração.

O programa teve um duplo caráter educativo formal $\mathrm{x}$ assistencial devido à participação de estagiários, mas poderia ter sido realizado sem servir de campo de ensino, com apenas o envolvimento da equipe de saúde do Posto e promotoras de saúde.

O pessoal de enfermagem (atendentes e auxiliares de enfermagem) participou de um curso sobre cuidados primários de saúde, com uma carga horária de 10 horas de teoria, sendo a prática desenvolvida e orientada no próprio serviço, sob a forma de educação continuada, mais intensificada no início (período de implantação). O curso e supervisão ficaram a cargo dos estudantes já treinados e professores de enfermagem.

As promotoras de saúde fizeram um treinamento inicial com 10 horas de teoria e 30 horas de prática (ver Quadro III) para realizarem várias atividadess, como visita domiciliar, educação para a saúde individual e em grupo e encaminhamentos. A prática era supervisionada diretamente, utilizando uma situação real na própria comunidade. Depois deste primeiro treinamento, houve dois cursos de reciclagem, dados anualmente em 1980 e 1981, baseados em avaliações feitas sobre o desempenho e dificuldades encontradas. Um dos cursos de reciclagem tinha como objetivo informar melhor sobre assuntos de maior interesse, relacionados a problemas locais mais freqüentes; dentre eles, os dois principais foram a desnutrição e o desmame precoce.

\subsubsection{Promotoras de Saúde}

A Associação de Promoção de Saúde nasceu da antiga Sociedade de Saúdè. Esta Sociedade, como já foi comentado, estava bastante motivada para realizar um trabalho em benefício da saúde da comunidade, mas sem organização definida.

Durante três meses do primeiro semestre de 1979, duas professoras do curso de enfermagem reuniram-se com esta Sociedade com o objetivo de definir a finalidade do grupo, discutir seu papel no desenvolvimento da comunidade e traçar uma metodologia de trabalho. Estas professoras já haviam trabalhado com o grupo, mesmo antes da formação da Sociedade de Saúde, e seu papel era de assessoria.

O nome da Sociedade de Saúde foi mudada para Associação de Promoção da Saúde, por decisão de seus associados, que também resolveram estabelecer alguns critérios para futuras sócias: idade igual ou superior a 18 anos, saúde física e mental, disponibilidade de tempo ( 8 a 10 horas semanais); interesse em trabalho comunitário, ser voluntário.

Partindo das discussões sobre os problemas de saúde dos bairros, o grupo achou que a forma de ajudar seria trabalhar diretamente com as famílias. A partir daí, o grupo fez uma listagem do que era importante saber para a realização do trabalho. Baseado nesta relação, foi elaborado o primeiro treinamento com objetivos concretos.

Para o trabalho se tornar mais fácil e organizado, os bairros foram divididos em várias áreas, com cada promotora se responsabilizando pela cobertura de uma área. Cada área tinha uma média de 75 a 100 casas. 
Vilar R.L.A. e Colaboradora - Avaliação de um Programa de Assistência Primária de Saúde na Área Periurbana. Rev. Bras. Enf.; RS.36: 199 - 212, 1983.

No início, foi feito um cadastramento das famílias pelas próprias promotoras, que aproveitaram a oportunidade para informar sobre o seu trabalho. Aquelas que não eram alfabetizadas levavam um filho que fazia as anotaçōes (cadastro). Assim, a atuação foi iniciada já no treinamento.

Foram encaminhadas gestantes e crianças ao Serviço de Pré-natal e Puericultura, através das visitas domiciliares. Orientações sobre vacinas, higiene, tratamento de doenças mais comuns e uso correto dos medicamentos também fizeram parte do trabalho.

Este trabalho pode ser avaliado quantitativamente, pois cada encaminhamento feito foi registrado por uma seta colorida no mapa do bairro existente no Centro de Saúde, que continha as divisões das áreas de cada promotora. Cada cor da seta correspondia a um tipo de encaminhamento.

Havia reuniōes quinzenais do grupo com a enfermeira para avaliar o trabalho qualitativamente e discutir problemas encontrados. Se a promotora necessitasse de ajuda durante o seu trabalho, poderia procurar a enfermeira no Centro de Saúde.

Após o primeiro ano de atividade, o grupo iniciou um trabalho de orientação coletiva. Eram realizadas reuniōes nas casas das promotoras, onde se discutiam os assuntos de interesse do grupo participante. Posteriormente, estas reuniōes passaram a ser feitas nas casas do pessoal do bairro, que se colocou disponível.

Foi também dada, neste segundo ano, uma atenção especial aos problemas de desmame precoce e desnutrição. Neste trabalho, foi formado um grupo semelhante à Liga de Leite Materno e incentivado o cultivo da horta escolar, além das orientaçōes dadas e encaminhamentos de casos de desnutrição de 2 . e 3 . grau.

Finalmente, as promotoras de saúde representavam o setor de saúde do bairro no conselho comunitário e sempre se envolviam nos trabalhos reivindicatórios para melhoria da comunidade. O primeiro chafariz público instalado nos dois bairros, Cidade Nova e Felipe Camarão, foi resultante disto.

Merece destaque aqui a real importância do caráter voluntário do trabalho. Uma promotora chegou a dizer, em uma das reuniōes, que, se houvesse pagamento, não seria tão eficiente, pois toda pessoa deveria ser educada para ser responsável pelo cuidado de sua saúde.

\section{METODOLOGIA E AVALIAÇÃO}

Para testar a hipótese de que o Programa de Assistência Primária de Saúde elevaria o nível de saúde da comunidade, foi elaborado um modelo de avaliação para examinar o relacionamento entre o programa e as variáveis dependentes.

Foi feito preliminarmente um levantamento detalhado dos conhecimentos, atitudes e práticas de saúde das quatro comunidades que utilizavam o Centro de Saúde da Cidade da Esperança. As características demográficas dos bairros e o nível nutricional das mães e crianças também foram documentados.

A vantagem deste modelo avaliativo é a seleção de grupos semelhantes e a medição do nível de saúde de cada grupo antes da intervenção. O modelo pode, então, controlar qualquer diferença já existente ou os efeitos do tempo e desenvolvimento fora do controle do programa nos dois grupos, durante todo o período da intervenção.

Modelo Avaliativo

$\begin{array}{lccc}\text { Grupo } & \text { Pré-teste } & \text { Intervenção } & \text { Pós-teste } \\ \text { Experimental } & 0 & x & 0 \\ \text { Controle } & 0 & & 0\end{array}$

No segundo semestre do ano de 1978, as quatro comunidades foram mapeadas, e as casas, enumeradas com colaboração da SUCAM, possibilitando assim a escolha de uma amostra de 100 casos 
Vilar R.L.A. e Colaboradora - Avaliação de um Programa de Assistência Primária de Saúde na Área Periurbana. Rev. Bras. Enf.; RS.36: 199 - 212, 1983.

por bairro. No ano seguinte, foi feito o levantamento já citado, através da aplicação de um questionário e da realização de uma avaliação nutricional das famílias da amostra. Os estudantes de Enfermagem executaram a avaliação antropométrica, física e alimentar, e o Laboratório Central da Secretaria de Saúde fez os exames parasitológicos e de hemoglobina.

Em seguida, o programa foi implantado, e, durante o período de 2 anos, foi realizada uma coleta trimestral de dados, documentando a utilização dos serviços e atuação das promotoras.

Em meio de 1981, foi iniciado o segundo levantamento, utilizando os mesmos instrumentos. A composição da amostra sofreu algumas modificaçōes, para poder medir, mais corretamente, os efeitos da aplicação do primeiro questionário e a participação na avaliação nutricional nos novos comportamentos.

Foi feita uma tentativa de encontrar as famílias entrevistadas em 1979, e aproximadamente $50 \%$ do grupo foi encontrado. Para completar a amostra, foram incluídas novas famílias, utilizando-se o mesmo método de amostragem. A coleta de dados procedeu como na fase pré-intervenção, contando com a colaboração e integração das mesmas instituições.

Os dados coletados nos dois períodos foram codificados para processamento pelo computador. Inicialmente foram analisadas as freqüências de indicadores selecionados, para depois se testarem estatisticamente as modificaçōes observadas.

\section{RESULTADOS E DISCUSSÕES}

Como os objetivos do programa visavam à promoção de boas práticas de saúde através de uma melhor utilização dos serviços comunitários e de saúde, conseqüentemente elevando o nível de saúde da comunidade, os resultados serão comentados, divididos em quatro áreas: a) conhecimento de saúde e doença, b) utilização dos serviços comunitários e de saúde, c) práticas de saúde, e d) nível de saúde.

Estes resultados representam uma análise preliminar e são referentes a um estudo dos indicadores selecionados, que medem mais diretamente as mudanças ocorridas. $\mathrm{O}$ estudo está sendo continuado no sentido de fazer uma análise mais profunda, que será apresentada em outro documento posteriormente.

a) conhecimento de saúde e doença:

A teoria educacional mostra que a mudança de comportamento envolve a área cognitiva (o conhecer), valorativa (valor dado ao conhecimento) e da ação (aquisição de prática). Neste item, analisaremos as áreas cognitiva e valorativa de alguns indicadores selecionados.

O questionário aplicado indagava sobre a causa, prevenção e tratamento de sintomas e doenças mais comuns nas crianças da comunidade.

Foi formulado um índice escolhendo 16 variảveis referentes a diarréia, desitratação e verminose, dando um peso crescente, baseado na resposta mais apropriada da maẽ.

A Tabela II mostra que, nos dois grupos, experimental e de controle, houve uma melhora significante. $\mathrm{O}$ experimental teve uma média de pontos mais alta, mas já iniciou com um valor maior.

Analisando os componentes do índice da Tabela III, pode-se observar que as comunidades experimentais tiveram uma melhora superior às de controle, nos itens que foram mais enfatizados pelo programa: prevenção da diárreia (alimentação higiênica e correta), causas e tratamento da desidratação (dar líquidos), e causas e tratamento da diarréia.

A atuação do programa, na área de planejamento familiar, foi no sentido de atender as solicitações dos clientes e orientar a importância do intervalo adequado entre as gestações.

Como podemos ver na Tabela III, a população das duas comunidades reconheceu o planejamento familiar como um direito do casal.

Foi formulado um índice composto dos métodos mais corretos (pílula anticoncepcional, condon, uso de espermaticidas, tabela, ligação de trompas) comumente utilizados pela população brasileira, e estabelecidos pesos para o reconhecimento destes métodos. Na Tabela II, verifica-se que, embora a diferença entre os dois grupos no pós-teste não tenha sido tão grande, foi significativo o ganho do grupo experimental.

Nos últimos anos, tem-se verificado que o Ministério da Saúde vem incentivando cada vez mais o aleitamento materno, e, no programa, isto também foi observado e pode ser consultado na Tabela IV. O percentual dos dois grupos que reconhecem o leite materno como a melhor alimentação para o recém-nascido aumentou uma média de $32,45 \%$, sendo que, no grupo experimental, o aumento foi de $6,1 \%$ a mais. 
Vilar R.L.A. e Colaboradora - Avaliação de um Programa de Assistência Primária de Saúde na Área Periurbana. Rev. Bras. Enf.; RS.36: 199 - 212, 1983.

b) utilização dos serviços comunitários e de saúde:

Os serviços a que aqui nos referimos visam prioritariamente à promoção da saúde e prevenção das doenças, sem deixar de dar também atenção ao tratamento. À medida que aumenta a sua utilização, há maior possibilidade de adoção de uma conduta que favoreça um melhor grau de saúde.

As orientações sucessivas e regulares, juntamente com o ambiente criado pela interação dos elementos do programa, tendem a reforçar e apoiar as mudanças de comportamento.

Entre os vários indicadores, apresentaremos a utilização da puericultura e do pré-natal, e, apenas no grupo experimental, a freqüência de contato entre as promotoras e as famílias.

A puericultura, nos dois grupos, experimental e controle, foi mais utilizada no pós-teste, como mostra a Tabela $\mathrm{V}$, sendo que o aumento foi mais considerável no grupo experimental. No prénatal, o grupo controle diminuiu a sua utilização no pós-teste, enquanto que o experimental novamente aumentou.

A atuação das promotoras de saúde, elemento-chave no desenvolvimento do programa, ocorreu apenas no grupo experimental, como já foi dito anteriormente. De acordo com a Tabela VI, durante o período da intervenção, foram visitadas $64,3 \%$ das famílias, e a distribuição das visitas, na Tabela VII, mostra que, dèstas 126 famílias ( $64,3 \%$ da população), 53,2 receberam 2 ou mais visitas.

c) práticas de saúde:

Provavelmente existem muitas práticas que conduzem a um melhor nível de saúde, mas o programa tentou enfatizar aquelas práticas que tinham mais influência no estado de saúde da população estudada e cuja aquisição estava dentro das possibilidades da família.

Foram selecionadas práticas para esta apresentação relacionada à imunização, ao aleitamento materno, à higiene e ao consumo alimentar.

A Tabela VIII ilustra que a cobertura das quatro vacinas exigidas pelo Ministério de Saúde para a faixa de 0 a 4 anos teve um aumento maior no grupo experimental.

Na Tabela IX, houve várias modificações interessantes. O grupo experimental teve um ganho maior no destino adequado de dejetos, comparado com o de controle. Entretanto, no destino do lixo, apesar de haver uma mudança positiva no grupo experimental, o ganho no grupo de controle foi três vezes maior. Acreditamos que isto se justifica pelo aumento considerável da coleta pública de lixo neste grupo (controle), segundo a Tabela X.

No que se refere ao tratamento adequado de água, houve um decréscimo grande nos dois grupos, e não temos dados para explicar o fato. Devido ao relacionamento comprovado entre água e saúde, é importante que a causa deste resultado seja esclarecida.

Pela Tabela XI, podemos concluir que houve um acréscimo na incidência e no tempo de amamentação nos dois grupos, sendo que, novamente, o ganho do grupo experimental foi maior.

\section{CONCLUSÃO E RECOMENI)AÇĀ()}

O processo de urbanização está ocorrendo nos dois grupos: no de controle e no experimental; entretanto, como havia sido iniciado anteriormente, no grupo de controle está numa fase mais adiantada.

Foram constatadas várias melhorias no grupo de controle. Umas ficaram evidentes nos dados coletados, como: abastecimento de água, coleta de lixo, eletrificação; outros foram discretamente observáveis, relacionadas a transportes, pavimentação de ruas e serviços gerais de atendimento ao público.

Mesmo com estas melhorias ambientais mais avançadas no grupo de controle, o grupo experimental teve um progresso mais crescente em relação à adoção de certas práticas de saúde, mostrando o efeito do programa, cuja atuação foi mais na conduta das pessoas.

Provavelmente, com a continuação do processo de urbanização e mais as mudanças na conduta, que se tornam habituais, o grupo experimental, atingirá um nível mais elevado de saúde.

É importante registrar que, para a fundamentação do programa, foram necessários vários anos de trabalho na área, antes da sua implantação. Para observação de resultados mais abrangentes, será preciso continuidade do programa.

Recomenda-se que:

Seja efetuada a outra avaliação no período de, no mínimo, 3 anos após esta primeira avaliação, para medir o resultado da continuidade do programa e o efeito da urbanização.

Seja feita uma avaliação para medir o efeito de apenas o processo de descentralização de serviço, sem a participação da promotora de saúde e em uma comunidade com as mesmas características. Desta forma, pode-se chegar a uma conclusão sobre a contribuição da sua atuação nos resultados finais. 
Vilar R.L.A. e Colaboradora - Avaliação de um Programa de Assistência Primária de Saúde na Área Periurbana. Rev. Bras. Enf.; RS.36: 199 - 212, 1983.

Seja feito um estudo etnográfico para investigar as causas da mudança no tratamento de água e a influência dos curandeiros na saúde da população.

Tabela I: Índice do Reconhecimento de Cinco Métodos de Planejamento Familiar.

\begin{tabular}{l|c|r}
\hline Grupo & Valor no Pré-teste & Valor no Pós-teste \\
\hline Experimental & 6.040 & 6.754 \\
\hline Controle & 6.505 & 6.693 \\
\hline
\end{tabular}

Tạbela II - Índice do Conhecimento de Causas, Prevenção e Tratamento das Doenças.

\begin{tabular}{|c|c|c|c|c|}
\hline \multirow[b]{2}{*}{ Componentes do Índice } & \multicolumn{2}{|c|}{ Grupo Experimental } & \multicolumn{2}{|c|}{ Grupo de Controle } \\
\hline & Pré-teste\% & Pós-teste\% & Pré-teste\% & Pós teste\% \\
\hline \multicolumn{5}{|l|}{ 1. Causas da verminose } \\
\hline 1.1.Beber água contaminada & .365 & .452 & .210 & .322 \\
\hline 1.2.Moscas & .060 & .126 & .070 & .141 \\
\hline 1.3.Andar descalço & .770 & .824 & .700 & .884 \\
\hline 1.4.Não lavar as mãos & .280 & .286 & .220 & .352 \\
\hline 1.5.Não lavar frutas e verduras & .140 & .256 & .150 & .226 \\
\hline $\begin{array}{l}\text { 2. Número de evacuaçōes por } \\
\text { diarréia. }\end{array}$ & .640 & 1.779 & 1.230 & 1.879 \\
\hline \multicolumn{5}{|l|}{ 3. Prevenção de diarréia } \\
\hline 3.1.Ferver água & .410 & .382 & .230 & .462 \\
\hline $\begin{array}{l}\text { 3.2. Alimentação higiênica e cor- } \\
\text { reta }\end{array}$ & .225 & .553 & .195 & .578 \\
\hline 3.3.Dar leite materno & .020 & .121 & .010 & .361 \\
\hline 3.4. Lavar e escaldar a mamadeira. & .010 & .191 & .105 & .161 \\
\hline \multicolumn{5}{|l|}{ 4. Tratamento de desidratação } \\
\hline 4.1.Dar líquidos & .345 & .603 & .420 & .588 \\
\hline 4.2.Levar ao médico & .810 & .764 & .755 & .779 \\
\hline 4.3.Levar ao hospital & .005 & .251 & .030 & .246 \\
\hline 5. Causas de Diarréia & .395 & .508 & .295 & .221 \\
\hline 6. Tratamento da Diarréia & 760 & 975 & 730 & 794 \\
\hline 7. Causas de Desidratação & .740 & .889 & .890 & .874 \\
\hline Valor no índice & 6.735 & 8.960 & 6.240 & 8.568 \\
\hline
\end{tabular}


Vilar R.L.A. e Colaboradora - Avaliação de um Programa de Assistência Primária de Saúde na Área Periurbana. Rev. Bras. Enf.; RS.36: 199 - 212, 1983.

Tabela III: Reconhecimento do Planejamento Familiar como Direito do Casal

\begin{tabular}{l|c|c|c|c}
\hline \multirow{2}{*}{ Resposta } & \multicolumn{2}{|c|}{ Grupo Experimental } & \multicolumn{2}{c}{ Grupo Controle } \\
\cline { 2 - 5 } & Pré-teste\% & Pós-teste\% & Pré-teste\% & Pós-teste\% \\
\hline Sim & 73.9 & 88.4 & 74.9 & 89.4 \\
\hline Não & 13.6 & 8.5 & 10.1 & 8.5 \\
\hline Não sabe & 12.6 & 3.0 & 15.1 & 2.0 \\
\hline Total & 100.1 & 99.9 & 100.1 & 99.9 \\
\hline
\end{tabular}

Tabela IV: Reconhecimento do Leite Materno como Melhor Alimento para o Recém-Nascido

\begin{tabular}{l|c|c|c|c}
\hline \multirow{2}{*}{$\begin{array}{l}\text { Tipo de } \\
\text { Alimentação }\end{array}$} & \multicolumn{2}{|c|}{ Grupo Experimental } & \multicolumn{2}{c}{ Grupo Controle } \\
\cline { 2 - 5 } & Pré-teste\% & Pós-teste\% & Pré-teste\% & Pós-teste\% \\
\hline Leite Materno & 56,5 & 92.0 & 56.0 & 85.4 \\
\hline Outro Leite & 40.5 & 7.0 & 40.0 & 14.1 \\
\hline Outro & 0.5 & 0.5 & 0.5 & - \\
\hline Não Sabe & 2.5 & 0.5 & 3.5 & 0.5 \\
\hline Total & 100.0 & 100.0 & 100.0 & 100.0 \\
\hline
\end{tabular}

Tabela V: Utilização dos Serviços do Pré-natal e Puericultura

\begin{tabular}{l|c|c|c|c}
\hline \multirow{2}{*}{ Serviço } & \multicolumn{2}{|c|}{ Grupo Experimental } & \multicolumn{2}{c}{ Grupo Controle } \\
\cline { 2 - 5 } & Pré-teste\% & Pós-teste\% & Pré-teste\% & Pós-teste\% \\
\hline Puericultura & 18.7 & 42.2 & 10.7 & 17.1 \\
\hline Pré-natal & 32.4 & 67.7 & 62.1 & 53.1 \\
\hline
\end{tabular}

Tabela VI: Familias Visitadas pelas Promotoras de Saúde nas Comunidades Experimentais.

\begin{tabular}{l|c}
\hline Visitado & \% do Total \\
\hline Não sabe & 2.0 \\
\hline Sim & 64.3 \\
\hline Não & 33.2 \\
\hline É promotora & 0.5 \\
\hline Total & 100.0 \\
\hline
\end{tabular}


Vilar R.L.A. e Colaboradora - Avaliação de um Programa de Assistência Primária de Saúde na Área Periurbana. Rev. Bras. Enf.; RS.36: 199 - 212, 1983.

Tabela VII: Distribuição das Visitas pelas Promotoras na População Visitadaı

\begin{tabular}{l|c}
\hline N. de Visitas & \% do Total \\
\hline 0 & 2.4 \\
\hline 1 & 44.4 \\
\hline 2 & 29.4 \\
\hline 3 & 11.9 \\
\hline 4 & 11.9 \\
\hline & 100.0 \\
\hline
\end{tabular}

Tabela VIII: Percentual das Crianças de 0 - 4 anos Imunizadas com as Quatro Vacinas Obrigatórias.

\begin{tabular}{l|c|c|c|c}
\hline \multirow{2}{*}{ Vacinas } & \multicolumn{2}{|c|}{ Grupo Experimental } & \multicolumn{2}{c}{ Grupo Controle } \\
\cline { 2 - 5 } & Pré-teste\% & Pós-teste\% & Pré-teste\% & Pós-teste\% \\
\hline B C G & 70.4 & 83.9 & 72.5 & 84.3 \\
\hline D T P & 57.3 & 81.9 & 64.0 & 81.8 \\
\hline SABIN & 64.3 & 94.5 & 69.5 & 93.9 \\
\hline SARAMPO & 51.8 & 89.9 & 54.0 & 88.8 \\
\hline
\end{tabular}

Tabela IX: Índice do Tratamento Adequado de Água e Destino Adequado do Lixo e dos Dejetos.

\begin{tabular}{l|c|c|c|c}
\hline \multirow{2}{*}{} & \multicolumn{2}{|c|}{ Grupo Experimental } & \multicolumn{2}{c}{ Grupo Controle } \\
\cline { 2 - 5 } & Pré-teste\% & Pós-teste\% & Pré-teste\% & Pós-teste\% \\
\hline Tratamento de água & .505 & .145 & .285 & .095 \\
\hline Destino do Lixo & .275 & .465 & .205 & .795 \\
\hline Destino dos Dejetos & .725 & .875 & .930 & .985 \\
\hline Total & 1.505 & 1.485 & 1.420 & 1.875 \\
\hline
\end{tabular}

Tabela X: Métodos Úsados para o Destino do Lixo nos Dois Grupos

\begin{tabular}{l|c|c|c|c}
\hline \multirow{2}{*}{ Método } & \multicolumn{2}{|c|}{ Grupo Experimental } & \multicolumn{2}{c}{ Grupo Controle } \\
\cline { 2 - 5 } & Pré-teste\% & Pós-teste\% & Pré-teste\% & Pós-teste \% \\
\hline Queimar & 7.0 & 11.1 & 4.0 & 3.0 \\
\hline Enterrar & 20.5 & 20.6 & 12.1 & - \\
\hline Coleta Municipal & - & 15.1 & 4.5 & 77.3 \\
\hline Jogar no Mato & 72.5 & 53.3 & 77.3 & 18.7 \\
\hline Outros & - & - & 2.0 & 1.0 \\
\hline Total & 100.0 & 100.1 & 99.9 & 100.0 \\
\hline
\end{tabular}


Vilar R.L.A. e Colaboradora - Avaliação de um Programa de Assistência Primária de Saúde na Área Periurbana. Rev. Bras. Enf.; RS.36: 199 - 212, 1983.

Tabela XI: Índice da Incidência e Tempo de Administração do Filho mais Novo.

\begin{tabular}{l|c|c|c|r}
\hline \multirow{2}{*}{} & \multicolumn{2}{|c|}{ Grupo Experimental } & \multicolumn{2}{c}{ Grupo Controle } \\
\cline { 2 - 5 } & Pré-teste\% & Pós-teste\% & Pré-teste\% & Pós-teste\% \\
\hline Amamentado & .820 & .924 & .865 & .884 \\
\hline Duração da Amamentação & 1.570 & 1.770 & 1.550 & 1.735 \\
\hline Valor Total & 2.390 & 2.694 & 2.415 & 2.619 \\
\hline
\end{tabular}

\section{SUMMARY}

A primary health care program was developed and implemented in two peri-urban communities of Natal, RN.

The principal objective of this program was to improve the level of health of the community and the key mechanism was community participation principally through the work of the health promotors.

Program development will be detailed along with an evaluation based on measurable changes in health pratices and health service utilization as observed in these two communities during a period of two years.

\section{BIBLIOGRAFIA E REFERÊNCIAS}

1. BRASIL, 1980 - IBGE, Anuário Estatístico do Brasil

2. BRASIL, 1979 - IBGE, Indicadores do Brasil, Relatório

3. BRASIL, 1981 - MEC, Secretaria de Ensino Superior - Programa de Integração DocenteAssistencial, Série Cadernos de Ciências da Saúde, n.o 3, Brasília.

4. BRASIL, 1981 - IBGE, Sinopse Preliminar do Censo Demográfico (1980) - Volume 1, no.9, Rio de Janeiro.

5. GOMEZ et alii, 1956 - Mortality in second and third Degree Malnutrition, The Journal of Tropical Pediatrics, September, 77-83.

6. MARCONDES, E. et alii, 1976 - Desnutrição. Monografias Médicas, Série Pediatria, Volume II, Sarvier S/A Editora, São Paulo.

7. MATOS, A. V., 1980 - Enfermagem e Assistência Primária de Saúde no Brasil - Anais do XXXII Congresso Brasileiro de Enfermagem, Brasília, 85-103.

8. OMS, UNICEF - Cuidados Primários de Saúde - Relatório da Conferência Internacional sobre Cuidados Primários de Saúde - Alma Alta, URSS, 6-12 de setembro, 1978.

9. SEMENZATO, G. and CASTRO, I. E., 1979 - The Child and the Urban Environment in Brazil (Documento apresentado em uma reunião da UNICEF no México em maio de 1979), Janeiro.

10. WERNER, D. and BOWER, B., 1982 - Helping Health Workers Learn, 1. ed., IThe Hesperian Foundation.

11. WERNER, D., August, 1980 - Health Care and Human Dignity - A Subjective look at Community rural health programmes in Latin American, Contact, n. 57, Christian Medical Comission. 